http://dx.doi.org/10.5902/1984686X32390

\title{
A narrativa de universitários cegos acerca de suas experiências acadêmicas
}

\author{
The narrative of blind college students about their \\ academic experiences
}

\section{La narrativa de universitarios ciegos sobre sus experiencias académicas}

\author{
* Danielle Sousa Silva \\ Doutoranda pela Universidade de Brasília, Brasília, Distrito Federal, Brasil. \\ dssfatima@gmail.com

\section{** Maristela Rossato} \\ Professora doutora na Universidade de Brasília, Brasília, Distrito Federal, Brasil. \\ maristelarossato@gmail.com

\section{*** Erenice Natalia Soares Carvalho \\ Professora na Associação Objetivo de Ensino Superior-ASSOBES, Brasília, Distrito Federal, Brasil. erenice@terra.com.br}

Recebido: 31 de novembro de 2018

Aprovado: 24 de janeiro de 2018

\section{RESUMO}

A educação inclusiva, enquanto modalidade transversal de ensino no Brasil tem exigido o desenvolvimento de estratégias pedagógicas no âmbito educacional na Educação Superior. Atualmente, observa-se um número crescente de estudantes com deficiência ingressos nas diversas universidades brasileiras em diferentes cursos de graduação. Esta situação traz desafios aos processos de organização de currículo, avaliação e promoção de estratégias que contribuam com o acesso, permanência e conclusão destes estudantes. Nesta linha, este artigo tem por objetivo analisar as narrativas de estudantes universitários cegos acerca de suas experiências acadêmicas no Ensino Superior visando contribuir para a abertura de novos campos de inteligibilidade sobre o processo de inclusão nesse nível de ensino. $O$ estudo foi desenvolvido em uma universidade brasileira (Distrito Federal), a partir da realização de entrevistas semiestruturadas com 02 estudantes cegos, durante um semestre letivo. A análise dos resultados culminou nos seguintes eixos temáticos: a) Os desafios curriculares, e b) Os sentidos acerca da inclusão acadêmica. Depreende-se da análise realizada, o desconhecimento por parte do universitário cego acerca dos direitos concernentes às estratégias adaptativas que devem ser acessadas no seu processo de escolarização. Além disso, as estratégias pedagógicas, quando desenvolvidas e ofertadas para os participantes, não se basearam em práticas pedagógicas específicas para o sujeito cego, mas em escolhas casuais e pessoais a depender dos seus respectivos professores. 
http://dx.doi.org/10.5902/1984686X32390

Palavras-chave: Deficiência visual; Ensino Superior; Experiências acadêmicas.

\begin{abstract}
Inclusive education, as a transversal modality of education in Brazil, has required the development of pedagogical strategies in the educational field in Higher Education. Currently, an increasing number of students with disabilities are admitted to various Brazilian universities in different undergraduate courses. This brings challenges to the processes of curriculum organization, evaluation and implementation of strategies that contribute to the access, permanent attendance and completion of the course. In this context, this article aims to analyze the narratives of blind university students about their academic experiences during Higher Education, aiming to contribute to the broadening of new fields of intelligibility about the process of inclusion in this level of education. The study was developed in a Brazilian university (Federal District), from the semi structured interviews with two blind students during a semester. The analysis of the study culminated in the following results: a) curricular challenges, and b) meanings of the academic inclusion. It can be inferred from the analysis carried out, the lack of knowledge on the part of blind students about their rights concerning access to proper adaptation throughout the schooling process. In addition, pedagogical strategies, when developed and offered to the participants, were not based on pedagogical practices aimed for the blind subject, but on casual and personal choices made by their respective teachers.
\end{abstract}

Keywords: Visual disability; Higher Education; Academic experiences.

\title{
RESUMEN
}

La educación inclusiva como modalidad transversal de la enseñanza en el Brasil ha exigido el desarrollo de estrategias pedagógicas en el ámbito educacional en la Educación Superior. Actualmente se observa un número creciente de estudiantes con deficiencia que han ingresado en las diversas universidades brasileñas en diferentes cursos de graduación. Esta situación genera desafíos a los procesos de organización de currículo, evaluación y promoción de estrategias que contribuyan con el acceso, permanencia y conclusión de estos estudiantes. En esta línea, este artículo tiene por objetivo analizar las narrativas de estudiantes universitarios ciegos acerca de sus experiencias académicas en la Enseñanza Superior, visando contribuir para la abertura de nuevos campos de inteligibilidad sobre el proceso de inclusión en ése nivel de enseñanza. El estudio fue desarrollado en una universidad brasileña (Distrito Federal), a partir de la realización de entrevistas semiestructuradas con 02 estudiantes ciegos, durante un semestre lectivo. El análisis de los resultados culminó en los siguientes ejes temáticos: a) Los desafíos curriculares, y b) Los sentidos acerca de la inclusión académica. Despréndese del análisis realizado, el desconocimiento por parte del estudiante universitario ciego acerca de los derechos concernientes a las estrategias adaptativas que deben ser accesados en su proceso de escolarización. Además de eso, las estrategias pedagógicas, en momentos en los cuales fueron ofertadas para los participantes, no se basaron en prácticas pedagógicas específicas para el sujeto ciego, sin embargo, en elecciones casuales y personales a depender de sus respectivos profesores. 
http://dx.doi.org/10.5902/1984686X32390

Palabras clave: Deficiencia visual; Enseñanza Superior; Experiencias académicas.

\section{Introdução}

A Convenção sobre os Direitos das Pessoas com Deficiência foi assinada pela Organização das Nações Unidas em 2007 e teve o Brasil como signatário. As discussões realizadas nesta Convenção (Brasil, 2008) tornou-se parte integrante da atual Constituição da República Federativa do Brasil (Brasil, 1988) com status de Emenda Constitucional, desde o ano de 2008. No Artigo 24 da Convenção sobre os Direitos das Pessoas com Deficiência (Brasil, 2008), alusivo à educação, preconiza-se o acesso das pessoas deficientes ao Ensino Superior, sem discriminação e com igualdade de condições. Para tanto, assegura-lhes os apoios necessários e a provisão de "adaptações razoáveis", na perspectiva da inclusão plena e do exercício de seus direitos.

Conquanto o ordenamento jurídico brasileiro seja convergente no que tange a essas metas, a prática educacional tem revelado dificuldades e desafios significativos para a vida acadêmica e a formação desses universitários. Um aspecto relevante a ser considerado diz respeito à acessibilidade curricular, com destaque para as demandas dos estudantes e as respostas educacionais oferecidas pelas instituições de Ensino Superior às suas necessidades específicas (Silva, 2013; Klauch \& Müller, 2013; Silva Júnior \& Hammes, 2014; Martins, 2016; Alexandrino, Souza, Bianchi, Macuch \& Bertolini, 2017).

A despeito da ampliação de oportunidades educacionais crescentes para essa população específica e o acesso ao ensino em diferentes níveis, torna-se emergente a necessidade de avaliação e promoção de estratégias favoráveis à sua permanência na instituição de Ensino Superior, com êxito na carreira acadêmica. A inobservância dessas medidas abre espaço para o fortalecimento de estigmas sociais, a criação de barreiras à aprendizagem e à participação no contexto escolar, comprometendo-lhes a futura inserção profissional. O fato demonstra a relevância de investigações e controvérsias envolvendo a inclusão de estudantes cegos no Ensino Superior. Diante do exposto, este artigo tem por objetivo analisar as narrativas de estudantes universitários cegos acerca de suas experiências acadêmicas no Ensino Superior visando contribuir para a abertura de novos campos de inteligibilidade sobre o processo de inclusão nesse nível de ensino. 


\section{O desenvolvimento da pessoa cega à luz da Psicologia Histórico-Cultural}

Os estudos sobre o desenvolvimento das pessoas com deficiência fizeram parte do arsenal investigativo de L. S. Vigotski (1986-1934), principal expoente da Perspectiva Histórico-Cultural, sobretudo no período de 1925 a 1929 (Nuernberg, 2008). Esses estudos estão reunidos nas Obras Escogidas, volume V, denominado de Fundamentos da Defectologia, que tem como pensamento fundante a necessidade de compreender 0 processo de desenvolvimento das pessoas com deficiência para além dos aspectos estritamente orgânicos, constituindo assim, uma análise qualitativa do desenvolvimento ancorada no aspecto cultural (Vigotski, 1997).

Assim, observa-se que ao falar do desenvolvimento atípico também se amplia a compreensão sobre a natureza psicológica do homem (Vigotski, 1997) uma vez que, o caráter subjetivo dos comportamentos humanos esteve presente nos estudos de Vigotski sobre crianças com deficiência (González Rey, 2007). Nessa perspectiva, compreende-se a psique humana "como um sistema complexo" (p. 120) e, este sistema complexo, em conjunto com os "problemas complexos da existência" (p. 121) compõe o psiquismo humano, o que resulta afirmar que o psiquismo humano e seus processos cognitivos são processos constituídos socialmente, tal como apontam Vigotski (1997) e Luria (1990) ao afirmarem que funções mentais ou neurológicas não atuam de modo separado do social, mas em combinação, formando-se de maneira peculiar nas pessoas com deficiência.

Dessa maneira, conclui-se que "as necessidades especiais não são propriedades ou exigências dos seres humanos, nem nascem com eles, mas se originam de um processo de produção material e social" (Lira \& Schlindwein, 2008, p.173), ou seja, os variados tipos de desenvolvimento atípico são marcadores sociais, e não algo meramente biológico.

Nesse movimento dialético, entre o homem e cultura, capaz de promover desenvolvimento, reflete-se, neste estudo, sobre o desenvolvimento da pessoa com deficiência visual: "não se pode resumir a deficiência a uma falta de visão (o defeito de um órgão singular), mas deve compreender a existência de uma reestruturação muito profunda de todas as forças do organismo e da personalidade". (Vigotski, 1997, p. 99).

Assim, mesmo diante do não funcionamento, ou de funcionamento parcial, de um órgão sensorial que possibilita a visão, a cegueira não pode ser associada diretamente a uma desvantagem social, mas, sim, com as possibilidades e os estímulos para a compensação que está diretamente ligada ao desenvolvimento psíquico. Logo, a 
http://dx.doi.org/10.5902/1984686X32390

compensação como força motriz no desenvolvimento da pessoa cega se constitui no drama das interações sociais (Del Río \& Álvarez, 2007), que implicam contradições e antagonismos perpassados pelas classes sociais e, de maneira mais enfática, pela própria escola. Conforme destacam Silva, Mendonça e Mieto (2015), os estudantes com deficiência enfrentam cotidianamente o preconceito, a insuficiente infraestrutura e a falta de capacitação dos profissionais para lidarem com as necessidades educativas especiais. Assim, observa-se que as relações interpessoais em torno da pessoa com deficiência são marcadas dramaticamente pela ausência de condições materiais e, em se falando do espaço escolar, pela falta de ações pedagógicas e interpessoais condizentes com o seu modo de aprender.

Dessa maneira, desvela-se a necessidade da pessoa forjar maneiras de participação social e coletiva que a viabilizem acessar o capital cultural a fim de reorganizar as suas funções à favor do desenvolvimento compensatório. Corroborando com Vigotski (1997), o desenvolvimento cultural compensa a deficiência, pois, para a pessoa cega, a linguagem compreende um meio de organizar os sentidos produzidos na sua experiência cotidiana.

Essa compreensão acerca da importância da coletividade nos processos compensatórios, mesmo diante das contradições que emergem nas relações interpessoais, revela as infinitas possibilidades de aprendizagem que a pessoa com deficiência visual pode internalizar por meio da linguagem, bem como por uma "comunicação completa e absolutamente adequada e de uma compreensão mútua com os videntes" (Vigotski, 1997, p. 107-108). Assim, medida em que a pessoa assume e explora o veículo da linguagem como sua força motriz, é possível recorrer a outros meios para superar as dificuldades em relação ao espaço e, consequentemente, desafiar a ideia reducionista que a pessoa com deficiência visual é quem apresenta a falta de visão (Nuremberg, 2008).

Assim, sob a ótica da Psicologia Histórica Cultural, o desenvolvimento da pessoa cega não apresenta diferenças em relação às possibilidades de aprendizagem de uma pessoa vidente; o que existe são formas distintas de acesso ao conhecimento. Além disso, acreditase que as trajetórias e experiências de vida ofertada e viabilizadas para a pessoa com deficiência visual constituem uma íntima relação no modo como ela irá forjar a sua relação com a deficiência e, assim, viabilizar mecanismos compensatórios, conforme discutiremos a seguir no processo de escolarização no Ensino Superior. 


\section{Universitários com deficiência visual e o Ensino Superior: desafios à aprendizagem}

O Ensino Superior no Brasil está se tornando mais acessível à população com deficiência, conforme os dados do último Censo Demográfico realizado no Brasil (INEP, 2016). Este aumento nos índices de estudantes neste nível de ensino está diretamente relacionado com a implementação, em 2008, da Política Nacional de Educação Especial na Perspectiva da Educação Inclusiva (Brasil, 2008) que garante o direito dos estudantes com deficiência, transtornos globais do desenvolvimento e altas habilidades ou superdotação, de frequentarem a sala de aula comum, e quando necessário receber atendimento educacional especializado (AEE) no turno contrário a escolarização regular. Notadamente, apesar do aumento progressivo, vale ressaltar que se faz necessário avançar, ainda mais, quanto à escolarização das pessoas com deficiência, sobretudo no Ensino Superior.

De acordo com o último Censo Brasileiro datado 2010 (IBGE, 2010) existem no país 45.606.048 milhões de pessoas autodeclaradas com algum tipo de deficiência no país, o que corresponde a um percentual de $23,91 \%$; desse contingente $6,7 \%$ frequentam algum curso superior. Diante desse panorama fazem-se necessárias medidas organizativas para adequar a estrutura das instituições, desde aspectos físicos até pedagógicos, a fim de receber esses estudantes (Silva, 2013). É fato que, no Brasil, ainda há carência de normativas que orientem o ensino das pessoas com deficiência na educação superior. $\mathrm{Na}$ contemporaneidade, tem-se privilegiado aspectos de acessibilidade física e arquitetônica. De acordo com Moreira (2005), por mais que ofereçam estruturas mínimas de acessibilidade física, a ausência de acessibilidade pedagógica é indicadora da pouca reflexão do mundo acadêmico para as demandas curriculares dos universitários.

Diante desse aspecto, questiona-se sobre a função do currículo em um processo de escolarização e, para isto recorre-se a Sacristán (1998), que elucida a relevância das funções do currículo, que se subdividem em 5 (cinco) aspectos: (1) a função social; (2) projeto ou plano educativo; (3) expressão formal e material; (4) campo prático; (5) atividade discursiva acadêmica e pesquisadora. Além disso, como prevê Pacheco (2011), observase que a dimensão curricular é movida continuamente por mudanças paradigmáticas relacionadas às transformações sociais e do conhecimento; excluindo assim, a possibilidade de obter uma concepção única e universalizante acerca do currículo, bem como dos elementos que o compõem, como "a organização curricular, organização modular, metodologia ativa, currículo nacional, as competências/metas de aprendizagem, 
e qualificação dos aprendentes" (Pacheco, 2011, p. 78). Mediante estes aspectos nota-se que os princípios de flexibilidade e da adaptação são inerentes a uma proposta curricular em face das necessidades culturais e da sociedade.

Para melhor compreender este processo na prática, recorre-se aos Parâmetros Curriculares Nacionais - PCNs (Brasil, 1997), que são referenciais que indicam conteúdos norteadores que devem ser ministrados ao longo do ano letivo, conforme cada ano/série. No entanto, no Ensino Superior brasileiro, não há esses referenciais curriculares em termos legais; o que existe são diretrizes curriculares em âmbito nacional para cada curso, de onde devem originar os projetos pedagógicos das IES. Portanto, as prerrogativas das disciplinas a serem ministradas ficam a cargo de cada IES, conforme a Resolução CNE/CES $n^{\circ} 2$, de 18 de junho de 2007 (BRASIL, 2007).

Em face das lacunas oriundas desses dispositivos legais sobre medidas a serem adotadas, especificadamente, com os universitários com deficiência, observa-se uma emergente necessidade de organização das IES para viabilizar o ingresso desses estudantes, bem como a permanência (com êxito) e a conclusão dos estudos neste nível de ensino. Para tanto, fazem-se necessárias medidas organizativas mais amplas capazes de influir desde a acessibilidade física à pedagógica, contemplando o currículo tanto na dimensão social, como a educativa. É necessário estabelecer um currículo compreensivo, dinâmico, interativo, e em contínua evolução, que tenha, como aspectos definidores, flexibilidade, abertura, autonomia e adequação, possibilitando diversificar respostas que se adaptem e proporcionem auxílios pedagógicos às especificidades e diferenças dos estudantes com deficiência (Silva, 2013).

Todavia, considera-se que alguns universitários com deficiência possam vir a demandar adaptações curriculares com a finalidade de viabilizar veículos que venham contribuir em seu acesso aos conteúdos acadêmicos, além de contribuir para sua participação na comunidade universitária. Para concretizar essa expectativa, a Lei Brasileira de Inclusão (Brasil, 2015) preconiza, no artigo 28, inciso III, a "provisão de adaptações razoáveis", para assegurar o acesso efetivo dessa população específica ao Ensino Superior. Adaptações razoáveis são definidas no Art. 2 da Convenção sobre os Direitos das Pessoas com Deficiência (Brasil, 2007), como "modificações e os ajustes necessários e adequados que não acarretem ônus desproporcional ou indevido, quando requeridos em cada caso, a fim de assegurar que as pessoas com deficiência possam gozar ou exercer, em igualdade de oportunidades com as demais pessoas, todos os direitos 
http://dx.doi.org/10.5902/1984686X32390

humanos e liberdades fundamentais". Além disso, no artigo 30 da Lei Brasileira de Inclusão (Brasil, 2015) se delimitam medidas que devem ser adotadas nos processos seletivos para ingresso e permanência dos estudantes com deficiência no Ensino Superior, seja público e privado.

Diante desses aspectos, para melhor discutir os desafios à aprendizagem curricular acessível para os universitários cegos e o Ensino Superior realizou-se um levantamento bibliográfico, em que se privilegiou estudos publicados no período de 2008 à 2018, nas bases de dados do Portal de Periódicos da CAPES/MEC, no Google Acadêmico e no Scientific Eletronic Library Online (Scielo-Brasil), a partir dos seguintes descritores: deficiência visual e Ensino Superior, deficiente visual e universidade; cego e Ensino Superior; cego e universidade. Inicialmente foram identificados 191 (cento e noventa e um) trabalhos entre artigos, livros, teses, dissertações e recursos audiovisuais; contudo fez-se necessário uma triagem dos materiais que melhor dialogassem com o objetivo deste trabalho, privilegiando assim, 4 (quatro) trabalhos advogados por Alexandrino et al. (2017), Klauch \& Müller (2013), Martins (2016) e Silva Júnior \& Hammes (2014).

O estudo apresentado por Silva Júnior \& Hammes (2014), configurou-se por uma pesquisa qualitativa do tipo de estudo de casos, com o objetivo de identificar, sob a ótica de 8 (oito) egressos cegos, estratégias que podem ser implementadas na universidade a fim de viabilizar a inclusão. Os dados foram obtidos por meio de entrevistas narrativas, que retrataram: as dificuldades nas relações com professores, uma vez que os docentes não compreendem as especificidades da pessoa cega quanto ao modo de acessar o conhecimento; o despreparo de profissionais de apoio, tais como ledores, que atuam diante dos universitários cegos imbuídos de crenças ancoradas no senso comum prejudicando, assim, o desempenho do estudante em suas atividades acadêmicas; a morosidade da instituição em disponibilizar os materiais pedagógicos em formato acessível; e, por fim, ausência de apoio institucional para acessar de maneira independente os espaços de apoio à sala de aula, como a biblioteca.

Na pesquisa de mestrado apresentada por Martins (2016), objetivou-se apresentar o processo educacional de estudantes com deficiência visual no Ensino Superior na Universidade Federal do Rio Grande do Norte (UFRN). O percurso metodológico adotado contemplou a abordagem qualitativa, por meio de Estudo de Caso. Participaram dessa investigação 7 (sete) docentes e 5 (cinco) discentes. As considerações da autora indicam que, atualmente, a inclusão das pessoas com deficiência no Ensino Superior configura-se 
http://dx.doi.org/10.5902/1984686X32390

como um processo em construção. Além disso, destaca a necessidade da oferta contínua de cursos de aperfeiçoamento com um víeis inclusivo para os entes institucionais. Por fim, Martins (2016) corrobora com Silva Júnior \& Hammes (2014) sobre a necessidade de consolidar uma formação continuada com os docentes visando discutir os aspectos relacionados à mediação pedagógica.

O trabalho apresentado por Klauch \& Müller (2013) apresentou como objetivo principal identificar as dificuldades enfrentadas por universitários com deficiência visual ao ingressarem no Ensino Superior. Também foi realizada uma pesquisa qualitativa, organizada por meio de estudo de casos. Os autores realizaram entrevistas semiestruturadas com 4 (quatro) acadêmicos do curso de Pedagogia da Universidade do Estado do Mato Grosso (UNEMAT). Os resultados indicaram à necessidade de consolidar institucionalmente políticas e práticas inclusivas que visem consolidar a inclusão das pessoas com deficiência visual no Ensino Superior, haja vista, que os participantes deste estudo enfatizaram o despreparo didático e estrutural das IES que recebem os universitários com deficiência, especificamente o deficiente visual.

Por fim, o trabalho apresentado por Alexandrino, Souza, Bianchi, Macuch \& Bertolini, (2017) buscou investigar por meio de entrevista semiestruturada junto a 1 (uma) egressa com deficiência visual, as dificuldades que emergiram ao longo da sua formação acadêmica no Ensino Superior. Essa pesquisa também utilizou do recurso de estudo de casos para acessar os dados que dialogassem com o objetivo desta investigação. Os autores concluíram que há uma ausência de materiais em formato acessível capazes de viabilizar o acesso aos conteúdos e a execução independente das atividades acadêmicas; há uma dissonância na comunicação entre professores e colaboradores técnicos-administrativos no que tange a resolução de medidas acadêmicas e administrativas que possam viabilizar a inclusão das pessoas com deficiência; além disso, destaca-se que há ausência de medidas de gestão estratégica capazes de garantir uma formação continuada para docentes no âmbito da inclusão, bem como de outras ações que possam vir a garantir o acesso, a permanência e a conclusão inclusiva no Ensino Superior.

Com efeito, as análises dos estudos apresentados indicam que os estudantes com deficiência visual, bem como outros tipos de deficiências e necessidades especiais, têm adentrando de maneira significativa no Ensino Superior. Notadamente, observa-se a existência de ações inclusivas que viabilizam o acesso a este nível de ensino, tal como preconiza a Lei Brasileira de Inclusão (Brasil, 2015). Todavia, esses estudos focalizam que 
http://dx.doi.org/10.5902/1984686X32390

os maiores desafios estão implicados no processo de permanência e conclusão do curso superior, de modo especial pela ausência de ações e adaptações curriculares que viabilizem a emergência dos aspectos compensatórios, como janelas de oportunidades diferenciadas para que a pessoa com deficiência atinja os mesmos objetivos formativos das pessoas sem uma deficiência (Nuernberg, 2008).

\section{Método}

Tendo como foco investigar os estudantes cegos e suas narrativas reflexivas acerca do ingresso no Ensino Superior, utilizou-se o delineamento metodológico qualitativo, que de acordo com Marconi e Lakatos (2004), compreende uma análise mais contextualista sobre os aspectos do comportamento e das relações estabelecidas pelo ser humano. Quanto à abordagem metodológica, realizou-se um estudo exploratório do tipo Estudo de Caso, que possibilita um conhecimento amplo e detalhado acerca do assunto estudado (Gil, 2007).

Os participantes desse estudo foram 2 (dois) universitários cegos de diferentes cursos de Graduação, de uma universidade no Distrito Federal (DF). Os participantes receberam nomes fictícios de José e Ana, com a finalidade de resguarda-los e cumprir os requisitos éticos ${ }^{1}$ estabelecidos na Resolução n 466/1996 (CNS, 1996) que versa sobre pesquisa com seres humanos.

Quanto aos instrumentos, foram utilizadas entrevistas semiestruturadas, uma vez que, de acordo com Duarte (2012), viabilizam uma flexibilidade no roteiro de entrevista oriundo da formulação de questões não-estruturadas. Além disso, as questões podem ser aprofundadas de acordo com a resposta dos participantes. As entrevistas foram realizadas individualmente e videogravadas em salas de aula da própria universidade, conforme a disponibilidade dos referidos estudantes e perfizeram uma duração média de 120 minutos cada.

Por fim, após a transcrição das entrevistas e análise integrada junto ao diário de campo, o tratamento dos dados depreendeu-se a partir da Análise de Conteúdo (Minayo, 2007), que culminou com a construção dos seguintes eixos temáticos, a) Os desafios curriculares, e b) Os sentidos acerca da inclusão acadêmica no Ensino Superior.

\footnotetext{
${ }^{1}$ Este trabalho foi aprovado pelo Comitê de Ética e Pesquisa; número do CAAE: 10719913.8.0000.0029
} 


\section{Resultados e discussão}

\section{Eixo A: Os desafios curriculares}

Neste eixo investigou-se sobre os desafios curriculares elencados pelos universitários cegos no Ensino Superior. Assim, quando questionados sobre os desafios curriculares que a pessoa com deficiência visual vivencia neste nível de escolarização, José relata: "é necessário adaptação, e não deve ser cobrada uma coisa para quem é normal, e uma coisa para quem é deficiente. [...] a mesma coisa que se passa para o deficiente, deve ser passado para a pessoa que é normal. [...] E em termos de currículo acadêmico, não é que a gente queira ser avaliado de forma diferente dos outros, a gente quer a mesma forma, mas [...] em compensação a gente precisa das adaptações". Este fragmento apresentado por José corrobora com o trabalho de Vigotski (1997) ao afirmar que o processo de aprendizagem das pessoas com deficiência obedece às mesmas leis das pessoas que apresentam desenvolvimento típico, embora, mediante algum tipo de limitação, faça-se necessário uma organização distinta, a depender da deficiência.

Ainda sobre este tema, Ana e José destacaram aspectos tangenciais ao currículo acadêmico como o acesso aos materiais de apoio aos estudos, o desconhecimento dos professores em adaptar uma aula para um universitário. Ana diz: "Eu acho, no meu ver, que os professores devem ser um pouco flexíveis, porque dependendo tem algumas atividades que não tem como a gente fazer. [...], eles devem, então, passar outro tipo de atividade para a gente fazer. [...] Eles devem ter uma flexibilidade em nossos trabalhos, dando outras sugestões". Ao encontro das reflexões de Ana, José acrescenta: “[...] adaptação deve ser tanto de espaço físico e acadêmico, também. [...] Inclui os textos da gente [...], questão de vídeos. [...] Os professores precisam começar a compreender que, se eles forem passar um vídeo, por exemplo, para os estudantes, devem procurar um vídeo que seja para a deficiência visual, um vídeo dublado. [...] A maioria coloca vídeos legendados. Muitas vezes esses vídeos que eles colocam legendados [...] não existem na versão dublada. Então, vamos começar a adaptar, [...] começar a retirar esse que só tem na versão legendada e substituir por um que tenha o mesmo significado, mas, porém, dublado; que é pra gente começar a ficar se situando". Na mesma linha José ainda complementa: "além da questão dos vídeos, dos filmes, tem a apresentação de slides. [...] tem muita coisa que o professor 
coloca a mais nos slides do que na própria fala dele. Ele deveria ter um pouco desse cuidado, pois tem gente nem sempre consegue visualizar".

Diante das colocações de Ana e José, reforça-se à luz da obra vigotskiana que os estudantes com deficiência, em algumas situações, demandam outros modos de organização das práticas educacionais para acessar o conhecimento, conforme retratado na fala de Ana. Neste sentido, Ana e José direcionam a responsabilidade de viabilizar as adaptações razoáveis ao docente, uma vez que, no Ensino Superior, cabe ao professor à incumbência de planejar e conduzir o processo educativo (Fontana, 2000). Todavia, não se trata de culpabilizar estritamente ao docente, mas de refletir sobre a importância da figura deste profissional para fomentar o conhecimento, bem como, a inclusão. Nesta mesma linha, faz-se necessário que o docente, ao se deparar com um universitário com desenvolvimento atípico, compreenda as suas especificidades e adote, por meio de ações formativas/continuadas, experiências favorecedoras da autonomia e da cidadania das pessoas com deficiência (Nuernberg, 2008; Martins, 2016).

Outro desafio que dialoga com os elementos curriculares sinalizados por Ana e José refere-se às atividades de verificação de conhecimento, notadamente conhecidas como provas. Neste contexto, verifica-se que o núcleo central dos sentidos atribuídos aos desafios curriculares na percepção dos participantes sinaliza uma desarmonia entre os dispositivos legais - universitário com deficiência - professor - e a instituição, algumas vezes, representadas por núcleos de apoio e/ou de acessibilidade ao estudante. Ana relata: "[...] peço permissão para gravar as aulas. A gente negocia de que forma a prova vai ser aplicada; se vai ser aplicada, se vai ser no computador, se vai ser oral. Tudo isso, geralmente, é resolvido no primeiro dia de aula, para depois não ter transtornos mais na frente. Porém, [...] às vezes, na época da prova eu não tenho todos os textos para estudar. Além disso, o jeito da aplicação da prova, que às vezes não favorece”. Nesta mesma linha, José diz: "o apoio que eu preciso e para realizar o processo de adaptação de materiais; que eu preciso nas provas. [...] Eu sempre preciso de um ledor para estar lendo, estar escrevendo as minhas respostas e estar marcando o que eu quero [...]. No caso, todas elas precisam que o professor passe não para mim diretamente, mas para o Núcleo de Apoio Institucional, com antecedência, para que o setor possa fazer o agendamento dessas adaptações [...]".

Observa-se nos relatos de Ana e José as contradições na qual são submetidos os estudantes com deficiência no Ensino Superior. De acordo com Nuernberg (2008, p. 314) 
http://dx.doi.org/10.5902/1984686X32390

mesmo diante de "leis e discursos que sustentam a educação inclusiva não se tem elucidado condições para a sua consolidação na prática". Diante disso, observa-se que os estudantes são impelidos a negociar com os professores adaptações razoáveis que são garantidas por lei, tal como realizar a avaliação em formato acessível (Brasil, 2015).

Outro aspecto que merece atenção refere-se à dificuldade dos universitários cegos em obterem os materiais de estudo, de modo acessível, no mesmo período em que são disponibilizados para os estudantes sem deficiência. Neste quesito, questiona-se quem deveria ser responsabilizado, pois não há dispositivos legais que ordenem sobre a periodicidade em que os materiais acessíveis devem ser disponibilizados. Ao mesmo tempo, o professor não se reconhece como profissional responsável por exigir que o material em meio acessível seja disponibilizado ao estudante. O estudante se vê impelido a realizar uma avaliação, para cumprir o prazo estipulado no cronograma de aula, sem dispor do material de estudo, por outro lado, os núcleos de apoio se vêem sobrecarregados com as demandas que chegam, e algumas vezes, mantendo as suas atividades com um quadro reduzido de profissionais (Silva, 2013; Martins, 2016; Silva Júnior \& Hammes, 2014; Klauch \& Müller, 2013). Em contrapartida, de acordo com Silva (2013) verifica-se que muitas vezes o estudante com deficiência é impelido a reunir estratégias em benefício próprio para se integrar ao contexto escolar, assumindo a incumbência de adequar o contexto educativo e, assim, eximindo a responsabilidade de outros membros e setores sociais, como professores, coordenadores, familiares, instituições educacionais, Secretaria de Educação e Ministério da Educação.

Assim, observa-se que a inclusão das pessoas com deficiência visual no Ensino Superior demanda uma maior articulação e organização dessas instâncias. Todavia, ainda assim, não é possível afirmar que estamos diante de um modo de organização efetivo para se consolidar a inclusão, pois se faz necessário conferir uma atenção para, "complexidade e a plasticidade do sistema psicológico" (Nuernberg, 2008, p. 314), além de articular com a análise dos sentidos acerca da inclusão, como discutiremos no eixo a seguir.

\section{Eixo B: Os sentidos acerca da inclusão acadêmica no Ensino Superior}

Neste eixo propõe-se analisar os sentidos atribuídos pelos universitários cegos às experiências e vivências que dialoguem com a inclusão no Ensino Superior. Por conseguinte, também se discute o impacto vivencial dessas experiências inclusivas na trajetória desses universitários. Assim, sobre este assunto Ana disse: "Eu estou aqui, neste curso, para entender melhor a mente humana, até eu mesma. [...] sei que eu necessito 
http://dx.doi.org/10.5902/1984686X32390

aprender mais. Mas, bem, [...] eu imagino que terei um bom futuro; apesar de sentir um pouco de medo de não conseguir alcançar os meus objetivos, e assim não tenha um futuro promissor. Contudo, [...] intimamente acredito que vou ter um bom futuro". Mediante a fala de Ana verifica-se que um dos sentidos a ela atribuído para ir ao encontro da inclusão acadêmica no Ensino Superior refere-se à expectativa de vivenciar um futuro promissor, ao associar o sucesso acadêmico e profissional. Para tanto, apesar da estudante ficar entre a ideia de um futuro promissor e o temor de não conseguir atingir este objetivo, ela reconhece que precisa aprender mais, aspecto este que dialoga com a proposição de Vigotski (1997), quando menciona que o êxito dos processos de compensação da pessoa com deficiência ocorre pela influência das relações socioculturais, como meio de propiciar aprendizagem e desenvolvimento.

Enquanto isso José relata: "Espero que eu consiga concluir agora, o meu curso. E, que de alguma forma eu tenha crescido dentro dessa universidade. Assim, eu posso deixar alguma coisa para aqueles que aqui vão ficar, ou vão passar por aqui. Eu acho que devo deixar um pouco da minha história aqui nessa IES, principalmente, para outros deficientes que estão aqui, que estão entrando nesse processo de fazer um curso de graduação. [...] enfim, eu preciso continuar a minha caminhada. Continuar lutando com outros deficientes [...] por esse espaço, que acho que é de extrema importância para todos”. Observa-se que os sentidos atribuídos por José revelam um compromisso social para com as pessoas com deficiência que estão no espaço universitário e, ao mesmo tempo, se configura como uma motivação pessoal, que possivelmente poderá a vir se constituir como uma aspiração profissional. Isso porque de acordo com Silva (2007, p.71) "as pessoas que apresentam uma deficiência, no caso, a deficiência visual, o trabalho tem a função também de realização, [...] e assume papel fundamental na construção da subjetividade, mesmo que esta seja influenciada pelas condições da sociedade capitalista, no mundo pós-moderno". Logo, aliar e compartilhar as suas tramas e experiências de luta, com outras pessoas com deficiência, para conseguir permanecer, e estar em vias de concluir o Ensino Superior, constitui-se em uma experiência que produz significado a sua própria existência.

Outro sentido atribuído por Ana acerca da inclusão acadêmica no Ensino Superior refere-se à necessidade de inclusão social por meio da inserção no mercado de trabalho. Sobre isto ela menciona: "Tenho dúvidas se vou conseguir um bom emprego. [...] hoje a minha principal ambição é terminar o meu curso superior e ter um bom emprego; contudo, eu temo, e gostaria de saber se vou ser uma boa profissional". Nesse relato, percebe-se a 
http://dx.doi.org/10.5902/1984686X32390

importância que a universitária atribui à formação acadêmica no Ensino Superior como via de obter um bom emprego e ser uma boa profissional. Essa discussão remete aos apoios necessários à acessibilidade do estudante com deficiência visual no seu processo de escolarização, conforme destaca Silva (2013). A acessibilidade deve ir além da dimensão física e estrutural, mas, sobretudo, contemplar as várias dimensões do currículo escolar, com o fim de potencializar as possibilidades de aprendizagem, em condições de igualdade com os seus pares que apresentam desenvolvimento típico.

Ainda sobre as condições de acessibilidade que devem ser ofertadas no Ensino Superior (Brasil, 2015), José da destaque para as medidas de apoio que são ofertadas pelos colegas da faculdade, bem como pelo núcleo de apoio ao estudante com deficiência, a saber: "Eu necessito sempre de apoio e de adaptações para o meu entendimento nas coisas da faculdade, daí eu conto com os meus colegas que nunca mediram esforços para me ajudar [...]. Além disso, conto com o núcleo de apoio ao estudante com deficiência. [...] é um serviço muito bom de apoio, pois eles compreendem as pessoas daqui. Eles compreendem a nossa vida, as nossas dificuldades; embora, eu saiba sei que existe uma demanda muito grande". Corroborando com Caiado (2014), Silva (2013), Padilha (2015) verifica-se que o posicionamento de José alude à necessidade de processos mediacionais a fim de oportunizar a constituição de significados que somente são possíveis nas relações sociais. Assim, o processo de escolarização do universitário com deficiência visual carece de uma rede de apoio capaz de possibilitar uma relação mais autônoma, e consequentemente uma relação mais efetiva entre o ensino e a aprendizagem.

\section{Considerações Finais}

Propor um espaço de reflexão sobre a inclusão da pessoa com deficiência no Ensino Superior é um desafio, uma vez que o princípio da educação superior está circunscrito em uma formação cidadã (Glat e Plestch, 2010). Partindo desse princípio, os estudantes que adentram neste nível de escolarização devem ser contemplados e posteriormente devem compartilhar conhecimentos e ações que expressem, por meio de suas profissões, 0 exercício da cidadania. Contudo, o que se observa são lacunas significativas para viabilizar um processo de aprendizagem e desenvolvimento cidadão e acessível, tal como previstos e chancelados nos dispositivos legais (Brasil, 2015).

Sobre os desafios curriculares verifica-se a presença pedagógica do professor como núcleo central desta discussão, uma vez que este, muitas vezes, recebe a incumbência de concretizar as adaptações razoáveis aos estudantes com deficiência, mesmo sem ter 
conhecimento adequado para essa ação por serem profissionais que advém de uma formação incipiente em relação à docência para estudantes com desenvolvimento atípico, sobretudo no Ensino Superior. No que tange os sentidos atribuídos pelos universitários com deficiência visual sobre a inclusão acadêmica, neste nível de ensino, verifica-se as tramas e os dramas vivenciados pelos universitários ao longo da sua trajetória de escolarização, os colocando em uma condição de acessar e valorizar os recursos mediacionais disponíveis, tal como os seus pares sem deficiência e o núcleo de apoio aos estudantes com deficiência, como meio propulsor para atingir os seus objetivos profissionais e pessoais.

Além disso, do ponto de vista da compensação e do processo de constituição do sujeito, destaca-se o movimento de ambos os participantes de buscarem meios próprios de adaptação e enfretamento diante das dificuldades enfrentadas no Ensino Superior. Sobre este assunto, verifica-se a ausência de pesquisas e reflexões mais aprofundadas acerca dos sentidos que mobilizam as pessoas com deficiência no ensino superior de darem continuidade ao seu processo de escolarização, apesar das lacunas ou precariedade de adaptações ainda presentes neste nível de ensino.

Em síntese, as discussões apresentadas reforçam a necessidade do Ensino Superior valorizar os recursos mediacionais capazes de viabilizar e oportunizar processos compensatórios. Ao priorizar esses recursos, pressupõe-se que sejam materializadas e, consequentemente, instituídas nas políticas e práticas pedagógicas institucionais uma atenção aos estudantes com deficiência.

Por fim, a atenção pedagógica ao currículo acadêmico para pessoas com deficiência, bem como do universitário cego, implica ações organizadas e criadoras com a finalidade de explorar as potencialidades e viabilizar que o universitário se sobreponha a deficiência, visto que a apropriação dos conhecimentos e conteúdos acadêmicos e historicamente partilhados viabilizará a participação e a compensação social.

\section{Referências}

ALEXANDRINO, Eduardo Gauze. et. al. Desafios dos estudantes com deficiência visual no Ensino Superior: um relato de experiência. Revista do Departamento de Educação Física e Saúde e do Mestrado em Promoção da Saúde da Universidade de Santa Cruz do Sul-Unisc. Santa Cruz do Sul-RS, v.18, n 1, jan/mar. (2017). Disponível em: <http://dx.doi.org/10.17058/cinergis.v18i1.8076>. Acesso em: 27 jan. 2018. 
http://dx.doi.org/10.5902/1984686X32390

BRASIL. Secretaria da Educação Fundamental. Parâmetros Curriculares Nacionais: introdução aos Parâmetros Curriculares Nacionais. MEC/ SEF. BrasíliaDF,1997.

BRASIL. Ministério da Educação. Resolução no 2, de 18 de junho de 2007. Dispõe sobre carga horária mínima e procedimentos relativos à integralização e duração dos cursos de graduação, bacharelados, na modalidade presencial, publicado no DOU de 13 de junho de 2007. Brasília-DF, 2007.

BRASIL. Política Nacional de Educação Especial na Perspectiva da Educação Inclusiva. Brasília-DF, 2008a. Disponível em: <http://portal.mec.gov.br/arquivos/pdf/politicaeducespecial.pdf>. Acesso em: 27 jan. 2018.

BRASIL. Secretaria Especial dos Direitos Humanos. Convenção sobre Direitos das Pessoas com Deficiência. Brasília-DF, 2008b.164p.

CAIADO, Kátia Regina Moreno. Estudante com deficiência visual na escola: lembranças e depoimentos. 3. ed. Campinas-SP: Autores Associados, 2014.

DAINEZ, Débora; SMOLKA, Ana. Luiza. Bustamante. O conceito de compensação no diálogo de Vigotski com Adler: desenvolvimento humano, educação e deficiência. Educ. Pesqui., São Paulo-SP, v. 40, n. 4, p. 1093-1108, out./dez. (2014). Disponível em: http://dx.doi.org/10.1590/S1517-97022014071545. Acesso em: 28 jan. 2018.

DEL RíO, Pablo; ÁlVARES, Amelia. De la Psicologia del drama al drama de la psicología: la relación entre la vida y la obra de Lev S. Vygotski. Estudios de Psicologia. v. 28, n. 3, p. 303-332.(2007). Disponível em: https://marxismocritico.files.wordpress.com/2012/06/de-la-psicologia-del-drama-aldrama-de-la-psicologia-la-relacion-entre-la-vida-y-la-obra-de-lev-s-vygotski.pdf. Acesso em: 28 jan. 2018.

DUARTE, Jorge. Entrevista em profundidade. In: DUARTE, Jorge; BARROS, Antônio (Eds.). Métodos e técnicas de pesquisa em comunicação. São Paulo-SP: Atlas, 2012. $62-83 \mathrm{p}$.

Fernandes, A. C. R.; Oliveira, M. C. S. L.; Almeida, L. S. (2016). Inclusão de estudantes com deficiências na universidade: estudo em uma universidade portuguesa. Psicologia Escolar e Educacional, São Paulo-SP. v. 20, n. 3, p. 483492.set/dez. (2016). Disponível em: http://dx.doi.org/10.1590/21753539/2015/02031024. Acesso em: 26 jan. 2018.

FONTANA, Roseli. A. Cação. Mediação Pedagógica na sala de aula. 3. ed. Campinas-SP: Autores Associados, 2000. 176p. 
http://dx.doi.org/10.5902/1984686X32390

GIL, Antônio Carlos. Métodos e Técnicas de Pesquisa Social. 5 ed. São Paulo-SP: Atlas, 2007. 220p.

GLAT, Rosana; PLESTCH, Márcia Denise. O papel da universidade no contexto da política de Educação Inclusiva: reflexões sobre a formação de recursos humanos e a produção de conhecimento. Revista Educação Especial. Santa Maria - RS, v. 23, n.38, p.345-356, set/dez. (2010). Disponível em: https://periodicos.ufsm.br/educacaoespecial/article/view/2095>. Acesso em: $1^{\circ}$ abr. 2018.

IBGE. Instituto Brasileiro de Geografia e Estatística. Censo Demográfico de 2010. Disponível em: http://censo2010.ibge.gov.br/>. Acesso em: 30 jan. 2018.

INEP. Instituto Nacional de Estudos e Pesquisa Educacionais Anísio Teixeira. Sinopse Estatística da Educação Superior 2015. Brasília-DF, 2016. Disponível em: <http://portal.inep.gov.br/basica-censo-escolar-sinopse-sinopse>. Acesso em: 30 jan. 2018.

LIRA, Miriam Cristina Frey de; SCHLINDWEIN, Luciane Maria. A pessoa cega e a inclusão: um olhar a partir da psicologia histórico-cultural. Cad. Cedes, Campinas-SP, v. $28, \quad$ n. 75 , p. 171-190, maio/ago. (2008). Disponível em: <http://www.scielo.br/pdf/ccedes/v28n75/v28n75a03.pdf>. Acesso em: 29 jan. 2018.

LURIA, Alexander Romanovich. Desenvolvimento cognitivo: seus fundamentos culturais e sociais. São Paulo-SP: Ícone, 1990

MARCONI, Marina de Andrade; LAKATOS, Eva Maria. Metodologia científica. São Paulo-SP: Editora Atlas, 2004.

MARTINS, Lisiê Marlene da Silveira Melo. Práticas e formação docente na UFRN com vistas à inclusão de estudantes cegos. Dissertação (Mestrado). Universidade Federal do Rio Grande do Norte. Programa de Pós-Graduação em Educação. NatalRN. (2016). 139 f. $\quad$ Disponível em: < https://repositorio.ufrn.br/jspui/bitstream/123456789/22407/1/LisieMarleneDaSilveira MeloMartins_DISSERT.pdf>. Acesso em: 29 jan. 2018.

MINAYO, Maria Cecília de Souza. O Desafio do Conhecimento: pesquisa Qualitativa em Saúde. 10. ed. São Paulo-SP: HUCITEC, 2007. 406 p.

MOREIRA. Laura Ceretta. In(ex)clusão na universidade: o estudante com necessidades educacionais especiais em questão. Revista Educação Especial, Santa Maria - RS, n.25, p.37-47, 2005. Disponível em: http://dx.doi.org/ 10.5902/1984686X. Acesso em: 30 jan. 2018. 
NUERNBERG, Adriano Henrique. Contribuições de Vigotski para a educação de pessoas com deficiência visual. Psicologia em Estudo, Maringá-PR, v.13, n.2, p.307316. (2008). Disponível em:<https://dx.doi.org/10.1590/S1413-73722008000200013>. Acesso em: 30 jan. 2018.

Observatório do PNE. Educação especial inclusiva. 2013. Disponível em: $<$ http://www.observatoriodopne.org.br/metas-pne/4-educacao-especial-inclusiva $>$. Acesso em: 26 jan. 2018.

PADILHA, Anna Maria Lunardi. Educação inclusiva: já se falou muito sobre ela? Educ. Foco, Juiz de Fora - MG, Edição Especial, p. 313-332. (2015). Disponível em: $<$ http://www.ufjf.br/revistaedufoco/files/2015/08/2-Ed-Foco-edicao-especial-PNAICscorte.pdf>. Acesso em: 29 jan. 2018.

PACHECO, José Augusto. Currículo, Aprendizagem e Avaliação: uma abordagem face à agenda globalizada. Revista Lusófona de Educação, v. 17, n. 17, p. 75-90. (2011).

Disponível

em: <http://revistas.ulusofona.pt/index.php/rleducacao/article/view/2366>. http://dx.doi.org/10.24140>. Acesso em: 12 mar. 2018.

REGIANI, Anelise Maria; MOL, Gerson de Souza. Inclusão de uma aluna cega em um Curso de Licenciatura em Química. Ciência \& Educação. Bauru-SP, v. 19, n. 1, p. 123-134. (2013). Disponível em: <http://dx.doi.org/10.1590/S151673132013000100009>. Acesso em: 12 mar. 2018.

SACRISTÁN. José Gimeno. O Currículo: uma reflexão sobre a prática. Trad. Ernani F. da Fonseca Rosa. 3. ed. Porto Alegre-RS: Artmed, 1998.

SILVA, Daniele Nunes Henrique; MENDONÇA, Fabiana Luiza Rezende; Mieto, Gabriela Sousa de Melo Mieto. O processo de inclusão de estudantes com deficiência intelectual: contradições e desafios nos modos de aprender e ensinar. In: MACIEL, Diva; BARBATO, Silviane (Eds.). Desenvolvimento Humano, Educação e Inclusão Escolar. Brasília-DF: Editora UnB, 2015. p. 209-223.

SILVA, Danielle Sousa da. Adequação curricular para o universitário cego: concepção, prática e desafios. Dissertação (Mestrado). Universidade Católica de Brasília. Programa de Pós Graduação em Psicologia. Brasília-DF. (2013). 142 f. Disponível em: < https://bdtd.ucb.br:8443/jspui/handle/123456789/1827>. Acesso em: 15 fev. 2018.

SILVA, Glaucia Pinheiro da. O Significado do Trabalho para o Deficiente Visual. Dissertação (Mestrado). Pontifícia Universidade Católica de Minas Gerais. Programa de Pós-Graduação em Psicologia. Belo Horizonte - MG. (2007). 107f. Disponível em: $<$ http://pucmg.br/documentos/dissertacoes_glaucia_silva.pdf>. Acesso em: $15 \mathrm{fev}$. 2018. 
SILVA JÚNIOR, Bento Selau da; HAMMES, Lúcio Jorge. (2014). Inclusão de cegos na educação superior: algumas estratégias para superação de obstáculos. X ANPED SUL, Florianópolis-SC, out. p. 1-19. (2014). Disponível em: <http://www.scielo.br/pdf/er/n28/a11n28.pdf>. Acesso em: 15 fev. 2018.

VIGOTSKI, Lev Semyonovich. Fundamentos de Defectología. Moscou: Editorial Pedagógica, 1997.

\section{Correspondência}

Danielle Sousa Silva- Universidade de Brasília, UnB - Brasília. CEP: 70910-900. Brasília, Distrito Federal, Brasil.

http://orcid.org/0000-0002-1825-0097

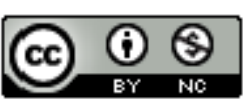

This work is licensed under a Creative Commons Attribution-NonCommercial 4.0 International (CC BY-NC 4.0) 